\title{
Temperature thresholds of ecosystem respiration at a global scale.
}

Article

Accepted Version

Johnston, A. S. A. ORCID: https://orcid.org/0000-0001-87814039, Meade, A., Ardö, J. ORCID: https://orcid.org/0000-00029318-0973, Arriga, N. ORCID: https://orcid.org/0000-00015321-3497, Black, A., Blanken, P. D. ORCID: https://orcid.org/0000-0002-7405-2220, Bonal, D. ORCID: https://orcid.org/0000-0001-9602-8603, Brümmer, C. ORCID: https://orcid.org/0000-0001-6621-5010, Cescatti, A., Dušek, J. ORCID: https://orcid.org/0000-0001-6119-0838, Graf, A. ORCID: https://orcid.org/0000-0003-4870-7622, Gioli, B. ORCID: https://orcid.org/0000-0001-7631-2623, Goded, I. ORCID: https://orcid.org/0000-0002-1912-325X, Gough, C. M. ORCID: https://orcid.org/0000-0002-1227-7731, Ikawa, H., Jassal, R. ORCID: https://orcid.org/0000-0002-6727-5215, Kobayashi, H. ORCID: https://orcid.org/0000-0001-9319-0621, Magliulo, V. ORCID: https://orcid.org/0000-0001-5505-6552, Manca, G. ORCID: https://orcid.org/0000-0002-9376-0310, Montagnani, L. ORCID: https://orcid.org/0000-0003-29579071, Moyano, F. E. ORCID: https://orcid.org/0000-0002-40905838, Olesen, J. E. ORCID: https://orcid.org/0000-0002-66391273, Sachs, T. ORCID: https://orcid.org/0000-0002-99594771, Shao, C., Tagesson, T. ORCID: https://orcid.org/00000003-3011-1775, Wohlfahrt, G. ORCID: https://orcid.org/00000003-3080-6702, Wolf, S. ORCID: https://orcid.org/0000-00017717-6993, Woodgate, W., Varlagin, A. ORCID: 
https://orcid.org/0000-0002-2549-5236 and Venditti, C.

ORCID: https://orcid.org/0000-0002-6776-2355 (2021)

Temperature thresholds of ecosystem respiration at a global scale. Nature Ecology \& Evolution, 5. pp. 487-494. ISSN 2397334X doi: https://doi.org/10.1038/s41559-021-01398-z Available at https://centaur.reading.ac.uk/96746/

It is advisable to refer to the publisher's version if you intend to cite from the work. See Guidance on citing.

To link to this article DOI: http://dx.doi.org/10.1038/s41559-021-01398-z

Publisher: Nature

All outputs in CentAUR are protected by Intellectual Property Rights law, including copyright law. Copyright and IPR is retained by the creators or other copyright holders. Terms and conditions for use of this material are defined in the End User Agreement.

\section{www.reading.ac.uk/centaur}

\section{CentAUR}

Central Archive at the University of Reading

Reading's research outputs online 


\section{Temperature thresholds of ecosystem respiration at a global scale}

2 Alice S.A. Johnston ${ }^{1,2 *}$, Andrew Meade ${ }^{2}$, Jonas Ardö ${ }^{3}$, Nicola Arriga ${ }^{4}$, Andy Black ${ }^{5}$, Peter D.

3 Blanken $^{6}$, Damien Bonal ${ }^{7}$, Christian Brümmer $^{8}$, Alessandro Cescatti $^{4}$, Jiří Dušek ${ }^{9}$, Alexander

4 Graf $^{10}$, Beniamino Gioli ${ }^{11}$, Ignacio Goded ${ }^{4}$, Christopher M. Gough ${ }^{12}$, Hiroki Ikawa ${ }^{13}$, Rachhpal

5 Jassal $^{5}$, Hideki Kobayashi ${ }^{14}$, Vincenzo Magliulo ${ }^{15}$, Giovanni Manca ${ }^{4}$, Leonardo

6 Montagnani ${ }^{16,17}$, Fernando E. Moyano ${ }^{18}$, Jørgen E. Olesen ${ }^{19}$, Torsten Sachs ${ }^{20}$, Changliang

7 Shao $^{21}$, Torbern Tagesson ${ }^{22}$, Georg Wohlfahrt ${ }^{23}$, Sebastian Wolf ${ }^{24}$, William Woodgate ${ }^{25,26}$,

$8 \quad$ Andrej Varlagin ${ }^{27}$, Chris Venditti ${ }^{2}$

$9{ }^{1}$ School of Water, Energy and Environment, Cranfield University, Bedfordshire, MK43 OAL, UK.

102 School of Biological Sciences, University of Reading, Reading, RG6 6BX, UK.

$11{ }^{3}$ Physical Geography and Ecosystem Science, Lund University Sölvegatan 12, Sweden.

$12{ }^{4}$ European Commission, Joint Research Centre (JRC), Ispra, Italy.

${ }^{5}$ Faculty of Land and Food Systems; University of British Columbia; Vancouver, BC V6T 1Z4, Canada.

${ }^{6}$ Department of Geography, University of Colorado, Boulder CO, USA 80309-0260.

${ }^{7}$ Université de Lorraine, AgroParisTech, INRAE, UMR Silva, 54000 Nancy, France.

8 Thünen Institute of Climate-Smart Agriculture, Bundesallee 65, 38116 Braunschweig, Germany.

${ }^{9}$ Global Change Research Institute of the Czech Academy of Sciences, CZ-60300 Brno, Czech Republic.

${ }^{10}$ Forschungszentrum Jülich, Institute for Bio- and Geosciences 3: Agrosphere, 52080 Jülich, Germany.

${ }^{11} \mathrm{CNR}$, Institute of Bioeconomy, 50145 Firenze, Italy.

12 Virginia Commonwealth University, Department of Biology, Richmond, VA 23234, USA

${ }^{13}$ Institute for Agro-Environmental Sciences, National Agriculture and Food Research Organization, Tsukuba, 305-8604, Japan

${ }^{14}$ Research Institute for Global Change, Institute of Arctic Climate and Environment Research, Japan Agency for Marine-Earth Science and Technology, Japan.

${ }^{15} \mathrm{CNR}$, Institute for Mediterranean Agriculture and Forest Systems, 8580040 Ercolano, Italy.

${ }^{16}$ Autonomous Province of Bolzano, Forest Services, Bolzano 39100, Italy.

${ }^{17}$ Faculty of Science and Technology, Free University of Bolzano, Bolzano 39100, Italy

${ }^{18}$ University of Goettingen, Bioclimatology, Büsgenweg 2, 37077 Göttingen, Germany

${ }^{19}$ Aarhus University, Department of Agroecology, Blichers Allé 20, 8830 Tjele, Denmark

${ }^{20}$ GFZ German Research Centre for Geoscience, Telegrafenberg, Potsdam, Germany

21 Institute of Agricultural Resources and Regional Planning, Chinese Academy of Agricultural Sciences, Beijing 100081, China.

22 Department of Geosciences and Natural Resources, University of Copenhagen, Öster Voldgade 10,

34 Copenhagen, Denmark.

$35 \quad{ }^{23}$ Department of Ecology, University of Innsbruck, 6020 Innsbruck, Austria.

3624 Department of Environmental Systems Science, ETH Zurich, 8092 Zurich, Switzerland.

$37 \quad{ }^{25}$ Land \& Water, Commonwealth Scientific and Industrial Research Organisation, 2601, Canberra, Australia

$38{ }^{26}$ School of Earth and Environmental Sciences, The University of Queensland, 4067, Queensland, Australia.

3927 A.N. Severtsov Institute of Ecology and Evolution, Russian Academy of Sciences, 119071, Leninsky pr.33,

40 Moscow, Russia

41 *Correspondence: a.s.johnston@cranfield.ac.uk 
Ecosystem respiration is a major component of the global terrestrial carbon cycle and is strongly influenced by temperature. The global extent of the temperature-ecosystem respiration relationship, however, has not been fully explored. Here, we test linear and threshold models of ecosystem respiration across 210 globally distributed eddy covariance sites covering the most extensive temperature range ever studied. We find thresholds to the global temperature-ecosystem respiration relationship at high and low air temperatures and mid soil temperatures, which represent transitions in the temperature dependence and sensitivity of ecosystem respiration. Annual ecosystem respiration rates show a markedly reduced temperature dependence and sensitivity compared to half-hourly rates, and a single mid-temperature threshold for both air and soil temperature. Our study indicates a distinction in the influence of environmental factors, including temperature, on ecosystem respiration between latitudinal and climate gradients at short (half-hourly) and long (annual) timescales. Such climatological differences in the temperature sensitivity of ecosystem respiration have important consequences for the terrestrial net carbon sink under ongoing climate change.

\section{Main}

Carbon losses from terrestrial ecosystems determine the direction and magnitude of carbonclimate feedbacks ${ }^{1,2}$. The trajectory of future climate change therefore depends on the biological processes that underpin ecosystem fluxes. Ecosystem respiration $\left(R_{e}\right)$, the cumulative respiration of autotrophs (plants) and heterotrophs (bacteria, fungi and animals), represents a major component of the global carbon cycle ${ }^{3}$. Temperature strongly influences $R_{e}$ through the laws of thermodynamics ${ }^{4-6}$, but the global extent of the temperature- $R_{e}$ relationship has not been fully explored ${ }^{7,8}$.

Temperature-mediated variations in $R_{e}$ are typically described as an exponential function in Earth system models (ESMs) ${ }^{2}$. That is, globally static $Q_{10}$ values of around 2 represent a doubling of ecosystem $\mathrm{CO}_{2}$ fluxes with an increase in temperature of $10{ }^{\circ} \mathrm{C}$, when all other terms are equal ${ }^{9}$. Empirical and theoretical studies, however, have documented conflicting temperature- $R_{e}$ relationships. Latitudinal shifts in the temperature sensitivity of $R_{e}$ have been observed in empirical studies, with ecosystems experiencing greater increases in $R_{e}$ with temperature at high, compared to mid and low, latitudes ${ }^{8,10,11}$. At the same time, global syntheses have proposed convergent temperature sensitivities of $R_{e}$ across different climates and ecosystem types ${ }^{4,12,13}$.

The influence of temperature on ecosystem respiration is mediated by the temperature sensitivity of individual physiology, community composition and biotic interactions of all the organisms inhabiting an ecosystem ${ }^{13,14}$. At the individual-level, metabolic rates scale with 
body mass and increase exponentially with temperature according to the Boltzmann factor, $e^{-E / k T}$, where $E$ is the activation energy $(\mathrm{eV}), k$ is the Boltzmann's constant $\left(8.62 \times 10^{-5} \mathrm{eV}\right.$ $\mathrm{K}^{-1}$ ), and $T$ is temperature (in Kelvin) ${ }^{6}$. Widescale application of the Boltzmann factor to individual metabolic rates has revealed a common value of $E$ between 0.6 and $0.7 \mathrm{eV}^{5,6,15}$. At the ecosystem-level, models based on metabolic theory indicate exponential temperature- $R_{e}$ relationships across diverse ecosystems with a value of $E$ surprisingly similar to individual metabolic rates $\left(0.65 \mathrm{eV} ; Q_{10} \sim 2.50^{4,13}\right)$. Yet, models of the temperature- $R_{e}$ relationship have focused on a limited temperature range between 0 and $30^{\circ} \mathrm{C}$, even though terrestrial ecosystems experience temperatures between -60 and $50{ }^{\circ} \mathrm{C}^{16}$.

In this study we test the generality of the temperature- $R_{e}$ relationship, described by a general ecosystem model, across the most extensive temperature range yet investigated. The model, founded in metabolic theory, gives the linear expression:

$$
\ln \left(R_{e}\right)=\frac{-E}{1,000 k}\left(\frac{1,000}{T}\right)+\ln \left[\left(b_{0}\right)(C)\right]
$$

where $\ln \left(R_{e}\right)$ is the natural logarithm of ecosystem respiration, in $\mathrm{W} \mathrm{ha}^{-1} ;(1,000 / T)$ is the reciprocal of absolute temperature; $b_{0}$ is the intensity of cellular metabolism; and $C$ is the size distribution of organisms (assumed to be independent of $R_{e}$ according to the energy equivalence rule $)^{4}$. The model predicts a general linear relationship between $(1,000 / T)$ and $\ln \left(R_{e}\right)$, with an expected slope ( $\bar{E}$ from hereon in) across diverse ecosystems equal to -7.50 $\mathrm{K}(0.65 \mathrm{eV} \text {, with a plausible range between }-2 \text { and }-11 \mathrm{~K} \text {, or } 0.2 \text { and } 1.2 \mathrm{eV})^{10}$. However, we would expect climatological differences in resource supply ${ }^{17,18}$ and community composition ${ }^{14,19}$ to alter $\bar{E}$ across the global temperature range. We would also expect divergent relationships between metabolism and resource supply with temperature to modify the temperature- $R_{e}$ relationship over time ${ }^{13,20}$.

\section{Results}

We test the global extent of the linear temperature- $R_{e}$ relationship predicted by metabolic theory, by applying the model presented in Eq. 1 to measurements across 210 globally distributed FLUXNET sites ${ }^{21}$ (Figure 1 and Supplementary Data 1). Both short-term (halfhourly) and long-term (annual) measurements were tested for air and soil temperature. The half-hourly FLUXNET dataset is presented with more conventional temperature and $R_{e}$ units in Extended Data 1. The linear model (Eq. 1) was compared to a threshold model, which accounts for variations in the activation energy $(\bar{E})$ in Eq. 1 above and below specified temperature breakpoints (see Methods). That is, the threshold model accounts for shifts in the temperature sensitivity of $R_{e}$ across the global temperature range, and explains latitudinal shifts in the temperature- $R_{e}$ relationship observed in empirical studies ${ }^{8,10,11}$. All 
models were linear mixed effects models and goodness of fit comparisons used Akaike

112 Information Criterion (AIC) measurements.

\section{Figure 1}

114 The threshold model, which integrated two temperature breakpoints of $-24.8 \pm 0.15$ and 15.1 $\pm 0.22{ }^{\circ} \mathrm{C}$, better explained $R_{e}$ rates over the global extent of air temperatures in the FLUXNET dataset than the linear model $(\triangle \mathrm{AIC}=3,839,265$, Figure 2$)$. Similar to previous findings $s^{4,13}$, the threshold model indicates a temperature sensitivity of $R_{e}$ indistinguishable from that of $-7.50 \mathrm{~K}(0.65 \mathrm{eV}$, dashed line in Figs. $2 \mathrm{a} \& \mathrm{~b})$ predicted by metabolic theory (likelihood ratio test: $\left.X^{2}=0, p=1\right)$ between temperature breakpoints $(\bar{E}=-7.42 \mathrm{~K}, 0.64 \mathrm{eV}$, $\mathrm{Q}_{10} \sim 2.45$ between 15.1 and $-24.8^{\circ} \mathrm{C}$, solid line in Fig. $2 \mathrm{~b}$ ). Evaluation of the linear model, on the other hand, gives an activation energy for global $R_{e}$ rates of $-7.30 \mathrm{~K}(0.63 \mathrm{eV}$, solid lines in Fig. 2a), significantly different from that predicted by metabolic theory (likelihood ratio test: $\left.X^{2}=20009, p<0.0001\right)$. Importantly, the threshold model indicates a lower temperature sensitivity of $R_{e}$ at higher temperatures $\left(\bar{E}=-2.84 \mathrm{~K}, 0.25 \mathrm{eV}, \mathrm{Q}_{10} \sim 1.41\right.$ above $\left.15.1^{\circ} \mathrm{C}\right)$ and extreme temperature sensitivity of $R_{e}$ at very low temperatures $\left(\bar{E}=-30.53 \mathrm{~K}, 2.64 \mathrm{eV}, \mathrm{Q}_{10} \sim\right.$ 40.79 below $-24.8^{\circ} \mathrm{C}$ ). The threshold model therefore primarily improves predictions, compared to the linear model, of the temperature- $R_{e}$ relationship at low and high latitude sites (Figs. $2 \mathrm{f} \& \mathrm{~g}$ ). High measured variability in $R_{e}$ across the global temperature range, however, likely reflects the interactive effects of disturbance events, plant phenology and soil water and nutrient limitation on ecosystem metabolism.

\section{Figure 2}

Given the importance of belowground communities in $R_{e}{ }^{14,19}$, linear and threshold models were tested for the global relationship between soil temperature and ecosystem respiration (Figure 2 and Supplementary Table 2). A single temperature threshold of $11.4 \pm 0.29^{\circ} \mathrm{C}$ emerged for soil temperature, with little evidence for a lower temperature breakpoint (likelihood ratio test: $X^{2}=0, p=1$ ). Above the temperature threshold, the activation energy of $R_{e}$ was lower than that observed for air temperature $\left(\bar{E}=-2.18 \mathrm{~K}, 0.19 \mathrm{eV}, \mathrm{Q}_{10} \sim 1.30\right)$, while below the temperature threshold the activation energy was steeper than that between air temperature thresholds $\left(\bar{E}=-13.37 \mathrm{~K}, 1.16 \mathrm{eV}, \mathrm{Q}_{10} \sim 5.05\right)$. The absence of a lower threshold for $R_{e}$ with soil temperature is likely explained by thermal insulation from snow cover at low temperatures ${ }^{22}$ resulting in much fewer observations, compared to air temperature, of the soil temperature- $R_{e}$ relationship below $0{ }^{\circ} \mathrm{C}$. To account for the relative uncertainties of eddy covariance measurements below $-20{ }^{\circ} \mathrm{C}^{23}$, alongside the emergence of a single temperature breakpoint for soil temperature, we tested the sensitivity of the air temperature threshold model to temperature ranges with few 
available measurements (Extended Data 2). Ecosystem respiration data were classified in 5 ${ }^{\circ} \mathrm{C}$ temperature intervals and intervals containing $<1 \%$ of all measurements $(\mathrm{n}<235,521)$ were defined as low frequency intervals. Such intervals were present at both high $\left(>36{ }^{\circ} \mathrm{C}\right)$ and low $\left(<-19^{\circ} \mathrm{C}\right)$ temperatures. Each low frequency temperature interval was removed one by one, as well as all together ( $\sim 1.8 \%$ of the dataset), to investigate the sensitivity of the threshold model. The test provides supporting evidence of the robustness of temperature breakpoints to the removal of each temperature interval one by one. However, there was no support for a lower temperature breakpoint $\left(-24.8^{\circ} \mathrm{C}\right.$ in Fig. $\left.2 \mathrm{~b} \& \mathrm{c}\right)$ when all low frequency intervals or all those $<-19^{\circ} \mathrm{C}$ were removed. Instead, a single temperature breakpoint of 14. $6^{\circ} \mathrm{C}$ emerged (Extended Data 3 and Supplementary Table 3). The lower air temperature breakpoint should therefore be considered with caution until more accurate $R_{e}$ measurements at low temperatures can be made. $R_{e}$ rates nevertheless display a sharp decline at lower temperatures for both air (Fig. 2b) and soil (Fig. 3b) temperatures.

Figure 3

Sharp declines in $R_{e}$ at low soil and air temperatures likely indicate pulse responses of soil respiration to rewetting and thawing events ${ }^{24}$, attributed to the suppression of microbial activity under water limitation in freezing conditions ${ }^{25}$ and an uncoupling of the temperature dependence of microbial respiration from thermodynamic laws ${ }^{26}$. Differences between global temperature- $R_{e}$ relationships for air and soil temperature at short timescales also suggest shifts in the contribution of aboveground and belowground communities to $R_{e}$ across the global extent of temperatures. For instance, a lower activation energy for the temperature- $R_{e}$ relationship at higher soil temperatures $\left(\bar{E}=-2.18 \mathrm{~K}>11.4 \pm 0.29{ }^{\circ} \mathrm{C}\right.$, Fig. 3), compared to air temperatures $\left(\bar{E}=-2.84 \mathrm{~K}>15.1^{\circ} \mathrm{C}\right.$, Fig. 2), could indicate a relative reduction in the contribution of belowground autotrophs and heterotrophs to $R_{e}$ in warmer climates. On the other hand, the lower threshold for the temperature- $R_{e}$ relationship at low air temperatures could reflect a temperature limit for the metabolism of aboveground communities, whereas the absence of a lower temperature threshold for soil temperature suggests the importance of belowground communities as components of $R_{e}$ in mild to cold climates.

Global air temperature thresholds were consistent across climates, but the goodness of fit of the threshold model (pseudo $\mathrm{r}^{2}$ and $\triangle \mathrm{AICs}$ compared to the linear model, Fig. 4) declined with a decrease in overall temperature range at lower latitudes. For instance, the temperature dependence of $R_{e}$ (variation in $R_{e}$ rates explained by temperature) was greater in cold, higher latitude, climates (tundra and boreal, $r_{m}^{2}>0.60$ ), compared to mild (temperate, $r_{m}^{2}=0.48$ ) and warm, low latitude, climates (mediterranean and tropical, $r_{m}^{2} \leq$ 0.09). In warmer climates, random effects had a much greater influence on $R_{e}$ than in mild or cold climates, with FLUXNET site and latitude explaining more variation in tropical and 
mediterranean ecosystems (Supplementary Table 4). Across the 210 sites, the threshold model better predicted the temperature- $R_{e}$ relationship in the majority of cases $(n=197$, Supplementary Data 1), while temperature explained more of the variation in $R_{e}$ rates at sites with greater temperature ranges and higher latitudes (and Extended Data 4).

$Q_{10}$ estimates from the threshold model reflect latitudinal shifts in the temperature sensitivity of ecosystem respiration, with tropical, mediterranean, temperate, boreal, and tundra climates yielding $Q_{10}$ values of $1.38 \pm 0.01,1.82 \pm 0.43,2.32 \pm 0.31,2.67 \pm 0.10$, and 2.90 \pm 0.12 respectively, compared to a global $Q_{10}$ of $2.26 \pm 0.35$, and higher $Q_{10}$ estimates based on the soil temperature threshold model (Supplementary Table 5). Empirical observations of $R_{e}$, soil respiration and carbon turnover rates are comparable with threshold model estimates of higher temperature sensitivities of $R_{e}$ at high-latitudes and lower temperature sensitivities of $R_{e}$ at low-latitudes ${ }^{10,27}$. Weaker temperature control in the linear model, similar to ESMs that implement static global $Q_{10}$ values, cannot capture shifts in $R_{e}$ temperature sensitivities across the global temperature range (Supplementary Table 5).

\section{Figure 4}

Annual temperature- $R_{e}$ relationships were analysed across site years to investigate whether climatological differences in the temperature dependence and sensitivity of $R_{e}$ emerge over longer timescales. The threshold model explained the temperature- $R_{e}$ relationship better than the linear model at longer timescales for both air and soil temperature (Fig. 5). Surprisingly, threshold models converged for air and soil temperature, with a single midtemperature breakpoint of $11.0 \pm 0.16^{\circ} \mathrm{C}$ (Figs $5 \mathrm{~b} \& \mathrm{~d}$ ). Above the temperature threshold, annual $R_{e}$ rates declined with increasing mean annual temperatures from mid to low latitudes, while the activation energy below the temperature threshold was markedly reduced (Figs $5 \mathrm{a} \& \mathrm{c}, \bar{E} \sim-4.90 \mathrm{~K}, 0.42 \mathrm{eV}$ ) compared to short timescales. Weaker temperature relationships at longer timescales is reflected by global $Q_{10}$ estimates of $1.34 \pm 0.55$ and 1.29 \pm 0.58 for air and soil temperature, respectively (Supplementary Table 6). An overall lack of $R_{e}$ variation explained by temperature $\left(r_{m}^{2}<0.14\right)$ likely reflects the importance of confounding effects from soil water, nutrient limitation, and resource availability, alongside thermal acclimation, at longer timescales. The threshold model was further consistent for annual soil respiration and air temperature measurements from the Global Soil Respiration Database ${ }^{28}$, with a single temperature breakpoint of $5.5^{\circ} \mathrm{C}$ (Extended Data 5 and Supplementary Table 6).

\section{Figure 5}


217 Our study shows how latitudinal shifts in $R_{e}$ temperature sensitivity at both short and long

218 timescales correspond to transitions in the global temperature- $R_{e}$ relationship across

219 temperature thresholds. Importantly, temperature thresholds also indicate differences in the

220 temperature dependence of $R_{e}$, with more variation in $R_{e}$ rates explained by temperature in

221 cold compared to warm climates. In cold climates, temperature strongly influences metabolic

222 activity of belowground microbial communities ${ }^{19,25,26}$. In warm climates, ecosystem

223 metabolism is limited by water and nutrient availability, and resource availability to biological

224 communities ${ }^{18,27,29-31}$.

225 Both the temperature sensitivity and dependence of annual $R_{e}$ rates is markedly reduced

226 compared to the short-term $R_{e}$ temperature response, suggesting the dominance of resource

227 effects on ecosystem metabolism at longer timescales ${ }^{13}$. For instance, primary production

228 directs carbon availability for ecosystem metabolism and typically shows a weaker

229 temperature dependence ${ }^{20,32}$. Nutrient availability further drives preferential allocation of

230 photosynthate $\mathrm{C}$ above- or below-ground, with consequences for carbon availability and

231 quality to different ecosystem components ${ }^{17}$.

232 Thresholds to the temperature- $R_{e}$ relationship shown here will undoubtedly result from

233 temporally divergent sensitivities between ecosystem components (e.g. below- and above-

234 ground, heterotrophic and autotrophic) and several environmental controls over time.

235 Variable acclimation of the different components of $R_{e}$ to these environmental controls may

236 further influence the temperature dependence and sensitivity of $R_{e}$ by modifying the

237 temperature response of catabolic and anabolic pathways ${ }^{33-35}$. Although we would expect

238 such mechanisms to occur as gradual state changes rather than the sharp breakpoints

239 described here, our study indicates consistent temperature thresholds at which ecosystem

240 metabolism changes at a global scale. However, such results need to be validated for

241 different ecosystem components as detailed measurements become available, and for

242 decadal timescales over which the influence of anthropogenic factors can be detected.

243 Biosphere feedbacks with future climate changes will be strongly influenced by the 244 temperature- $R_{e}$ relationship ${ }^{36,37}$ and latitudinal shifts in $R_{e}$ temperature sensitivity as 245 identified here will have important consequences for the global net land carbon sink ${ }^{38}$. For

246 instance, while huge stores of labile carbon in permafrost regions could be released if 247 temperatures rise above lower thresholds for microbial decomposition ${ }^{26}, \mathrm{CO}_{2}$ fertilisation in 248 tropical and boreal regions could enhance carbon gains through primary production relative 249 to losses through $R_{e}{ }^{30,39}$. Climate change forecasts by ESMs would thus be improved by 250 accounting for temperature thresholds of $R_{e}$ at a global scale. A higher resolution 
understanding of $R_{e}$-climate feedbacks, however, requires strategic disentangling of the multiple environmental controls on the aboveground, belowground, heterotrophic, and autotrophic components of terrestrial ecosystem carbon fluxes.

\section{Methods}

\section{The FLUXNET dataset}

FLUXNET is a global network of micrometeorological sites providing eddy covariance $\mathrm{CO}_{2}$ exchange observations between terrestrial ecosystems and the atmosphere ${ }^{21}$. The FLUXNET 2015 dataset used in this study provides half hourly temperature and night-time $R_{e}$ measurements over 1454 site years and a latitudinal range of $78.92{ }^{\circ} \mathrm{N}$ to $37.43^{\circ} \mathrm{S}$. Observations across the 210 sites, which range from arctic tundra to tropical rainforest ecosystems, provide an extensive temperature range of $89.7{ }^{\circ} \mathrm{C}$, from -43.4 to $46.3^{\circ} \mathrm{C}$ (Figure 1 and Supplementary Data 1 ).

The FLUXNET dataset is subject to a data processing pipeline which include data quality controls checks, filtering of low turbulence periods and partitioning of $\mathrm{CO}_{2}$ fluxes into respiration and photosynthesis components using established methods ${ }^{21}$. Disentangling respiration and photosynthesis fluxes during the day is complex and the extraction of $R_{e}$ relies on modelling techniques with high uncertainty. Night-time $\mathrm{CO}_{2}$ exchange measurements thus provide the best approximation of $R_{e}$, and uncertainty has been minimised for the FLUXNET dataset by employing quality control procedures ${ }^{21}$. Here, nongap-filled half hourly $\left(\mu \mathrm{mol} \mathrm{CO}_{2} \mathrm{~m}^{-2} \mathrm{~s}^{-1}\right)$ and annual $\left(\mathrm{g} \mathrm{C} \mathrm{m}^{-2}\right)$ night-time $R_{e}$ (RECO_NT_VUT_MEAN), air temperature (TA_F) and soil temperature (TS_F) measurements were compiled from the FLUXNET 2015 dataset (https://fluxnet.fluxdata.org/data/fluxnet2015-dataset/). $R_{e}$ measurements were then converted to units of metabolic energy $\left(\mathrm{W} \mathrm{ha}^{-1}\right)^{4}$ by taking $0.272 \mathrm{~J} \mu \mathrm{mol} \mathrm{CO}_{2}$ and $10,000 \mathrm{~m}^{2}$ ha $^{-1}$.

\section{Model analysis}

The linear model (1) for describing the temperature- $R_{e}$ relationship was fitted to the global FLUXNET dataset, for both air and soil temperature. To test for the presence of temperature thresholds to the linear temperature- $R_{e}$ model at a global scale, which explain shifts in $R_{e}$ temperature sensitivity across climates, we compare the linear model in Eq. 1 to a threshold (piecewise) model. The threshold model, with two temperature breakpoints, gives:

$$
\left.\ln (R e)=\bar{E}_{1} f_{1}\left(1,000 / T, k_{1}\right)+\bar{E}_{2} f_{2}\left(1,000 / T, k_{1}, k_{2}\right) k 2\right)+\bar{E}_{3} f_{3}\left(1,000 / T, k_{2}\right)+\ln \left[\left(b_{0}\right)(C)\right]
$$

where $\bar{E}_{1}, \bar{E}_{2}$ and $\bar{E}_{3}$ represent activation energies for different temperature $(1,000 / T)$ ranges, determined by the two temperature breakpoints $\left(k_{1}\right.$ and $\left.k_{2}\right)$ and $f$ represents the functions: 


$$
f_{2}=\left\{\begin{aligned}
0, & 1,000 / T \leq k_{1} \\
1,000 / T-k_{1}, & k_{1} \leq 1,000 / T \leq k_{2} \\
k_{2}-k_{1}, & 1,000 / T>k_{2}
\end{aligned}\right.
$$

$$
f_{3}= \begin{cases}0, & 1,000 / T \leq k_{2} \\ 1,000 / T, & 1,000 / T>k_{2}\end{cases}
$$

The threshold model first introduced a single temperature breakpoint to the linear model, so that the activation energy $(\bar{E}$, with more negative values indicating higher temperature sensitivity) varies above and below a specified temperature. Temperature breakpoints were tested for the temperature $(1,000 / T)$ range between 3.1 and 4.4 , for every increment of 0.001 $\left(\sim 0.07^{\circ} \mathrm{C}\right)$. Differences in linear and threshold model AIC's were then compared for every temperature breakpoint. The highest $\triangle \mathrm{AIC}$ was taken as providing the most support for a temperature breakpoint, as long as $\triangle \mathrm{AIC}>5$ for additional degrees of freedom and $p<0.05$ in a likelihood ratio test. Then, the threshold model integrated an additional temperature breakpoint, taking the first temperature breakpoint with the greatest support as a fixed value. Model AIC's for each second temperature breakpoint were compared to the single threshold model and the second threshold was selected based on the highest $\triangle \mathrm{AIC}$ given the conditions outlined above. Temperature breakpoints were identified for short (half-hourly) and long (annual) temperature- $R_{e}$ relationships.

All models were linear mixed effects models, with FLUXNET site and latitude set as random effects. First, the models were tested for the global dataset and then for broadly classified climate zones (cold, mild, and warm) and climates (tundra, boreal, temperate, mediterranean, and tropical). Some generalisations were necessary during climate classification. For instance, alpine sites at mid-latitudes were classified as boreal climates (Supplementary Data 1). Linear and threshold models were further tested for each FLUXNET site. Finally, annual $R_{e}$ rates were used to investigate changes in temperature breakpoints, and linear and threshold model performance, at long timescales for air and soil temperature. Long timescale models accounted for latitude and year as random effects.

\section{References}

1. Cao, M. \& Woodward, F. I. Dynamic responses of terrestrial ecosystem carbon cycling to global climate change. Nature 393, 249-252 (1998). 
2. Heimann, M. \& Reichstein, M. Terrestrial ecosystem carbon dynamics and climate feedbacks. Nature 451, 289-292 (2008).

3. Allen, A. P., Gillooly, J. F. \& Brown, J. H. Linking the global carbon cycle to individual metabolism. Funct. Ecol. 19, 202-213 (2005).

4. Enquist, B. J. et al. Scaling metabolism from organisms to ecosystems. Nature 423, 639-642 (2003).

5. Gillooly, J. F., Brown, J. H., West, G. B., Savage, V. M. \& Charnov, E. L. Effects of size and temperature on metabolic rate. Science 293, 2248-2251 (2001).

6. Brown, J. H., Gillooly, J. F., Allen, A. P., Savage, V. M. \& West, G. B. Toward a metabolic theory of ecology. Ecology 85, 1771-1789 (2004).

7. Friedlingstein, P. et al. Uncertainties in CMIP5 climate projections due to carbon cycle feedbacks. J. Clim. 27, 511-526 (2014).

8. Davidson, E. A. \& Janssens, I. A. Temperature sensitivity of soil carbon decomposition and feedbacks to climate change. Nature 440, 165-173 (2006).

9. Lenton, T., M. \& Huntingford, C. Global terrestrial carbon storage and uncertainties in its temperature sensitivity examined with a simple model. Glob. Change Biol. 9, 1333-1352 (2003).

10. Song, B. et al. Divergent apparent temperature sensitivity of terrestrial ecosystem respiration. J. Plant Ecol. 7, 419-428 (2014).

11. Lloyd, J. \& Taylor, J. A. On the temperature dependence of soil respiration. Funct. Ecol. 315-323 (1994).

12. Mahecha, M. D. et al. Global Convergence in the Temperature Sensitivity of Respiration at Ecosystem Level. Science 329, 838-840 (2010).

13. Yvon-Durocher, G. et al. Reconciling the temperature dependence of respiration across timescales and ecosystem types. Nature 487, 472-476 (2012).

14. Johnston, A. S. A. \& Sibly, R. M. The influence of soil communities on the temperature sensitivity of soil respiration. Nat. Ecol. Evol. 2, 1597-1602 (2018). 
15. Dell, A. I., Pawar, S. \& Savage, V. M. Systematic variation in the temperature dependence of physiological and ecological traits. Proc. Natl. Acad. Sci. 108, 1059110596 (2011).

16. Buckley, L. B. \& Huey, R. B. Temperature extremes: geographic patterns, recent changes, and implications for organismal vulnerabilities. Glob. Change Biol. 22, 38293842 (2016).

17. Gill, A. L. \& Finzi, A. C. Belowground carbon flux links biogeochemical cycles and resource-use efficiency at the global scale. Ecol. Lett. 19, 1419-1428 (2016).

18. Green, J. K. et al. Large influence of soil moisture on long-term terrestrial carbon uptake. Nature 565, 476-479 (2019).

19. Allison, S. D., Wallenstein, M. D. \& Bradford, M. A. Soil-carbon response to warming dependent on microbial physiology. Nat. Geosci. 3, 336-340 (2010).

20. Michaletz, S. T., Cheng, D., Kerkhoff, A. J. \& Enquist, B. J. Convergence of terrestrial plant production across global climate gradients. Nature 512, 39-43 (2014).

21. Pastorello, G. et al. The FLUXNET2015 dataset and the ONEFlux processing pipeline for eddy covariance data. Sci. Data 7, 225 (2020).

22. Monson, R. K. et al. Winter forest soil respiration controlled by climate and microbial community composition. Nature 439, 711-714 (2006).

23. Mauder, M. et al. A strategy for quality and uncertainty assessment of long-term eddycovariance measurements. Agric. For. Meteorol. 169, 122-135 (2013).

24. Kim, D.-G., Vargas, R., Bond-Lamberty, B. \& Turetsky, M. R. Effects of soil rewetting and thawing on soil gas fluxes: a review of current literature and suggestions for future research. Biogeosciences 9, 2459-2483 (2012).

25. Du, E. et al. Winter soil respiration during soil-freezing process in a boreal forest in Northeast China. J. Plant Ecol. 6, 349-357 (2013).

26. Schuur, E. A. et al. Climate change and the permafrost carbon feedback. Nature 520, 171-179 (2015). 
27. Koven, C. D., Hugelius, G., Lawrence, D. M. \& Wieder, W. R. Higher climatological temperature sensitivity of soil carbon in cold than warm climates. Nat. Clim. Change 7, 817-822 (2017).

28. Bond-Lamberty, B. P. \& Thomson, A. M. A Global Database of Soil Respiration Data, Version 4.0. ORNL DAAC (2018) doi:https://doi.org/10.3334/ORNLDAAC/1578.

29. Zhang, Z. et al. A temperature threshold to identify the driving climate forces of the respiratory process in terrestrial ecosystems. Eur. J. Soil Biol. 89, 1-8 (2018).

30. Yang, Y., Donohue, R. J., McVicar, T. R., Roderick, M. L. \& Beck, H. E. Long-term CO2 fertilization increases vegetation productivity and has little effect on hydrological partitioning in tropical rainforests. J. Geophys. Res. Biogeosciences 121, 2125-2140 (2016).

31. Fleischer, K. et al. Amazon forest response to CO 2 fertilization dependent on plant phosphorus acquisition. Nat. Geosci. 12, 736-741 (2019).

32. Padfield, D. et al. Metabolic compensation constrains the temperature dependence of gross primary production. Ecol. Lett. 20, 1250-1260 (2017).

33. Atkin, O. K. \& Tjoelker, M. G. Thermal acclimation and the dynamic response of plant respiration to temperature. Trends Plant Sci. 8, 343-351 (2003).

34. Huntingford, C. et al. Implications of improved representations of plant respiration in a changing climate. Nat. Commun. 8, 1602 (2017).

35. Niu, S. et al. Thermal optimality of net ecosystem exchange of carbon dioxide and underlying mechanisms. New Phytol. 194, 775-783 (2012).

36. Rind, D. The Consequences of Not Knowing Low- and High-Latitude Climate Sensitivity. Bull. Am. Meteorol. Soc. 89, 855-864 (2008).

37. Liu, Z. et al. Increased high-latitude photosynthetic carbon gain offset by respiration carbon loss during an anomalous warm winter to spring transition. Glob. Change Biol. 26, 682-696 (2020).

38. Haverd, V. et al. Higher than expected $\mathrm{CO} 2$ fertilization inferred from leaf to global observations. Glob. Change Biol. 26, 2390-2402 (2020). 
396

397

398

399

400

401

402

403
39. Tagesson, T. et al. Recent divergence in the contributions of tropical and boreal forests to the terrestrial carbon sink. Nat. Ecol. Evol. 4, 202-209 (2020).

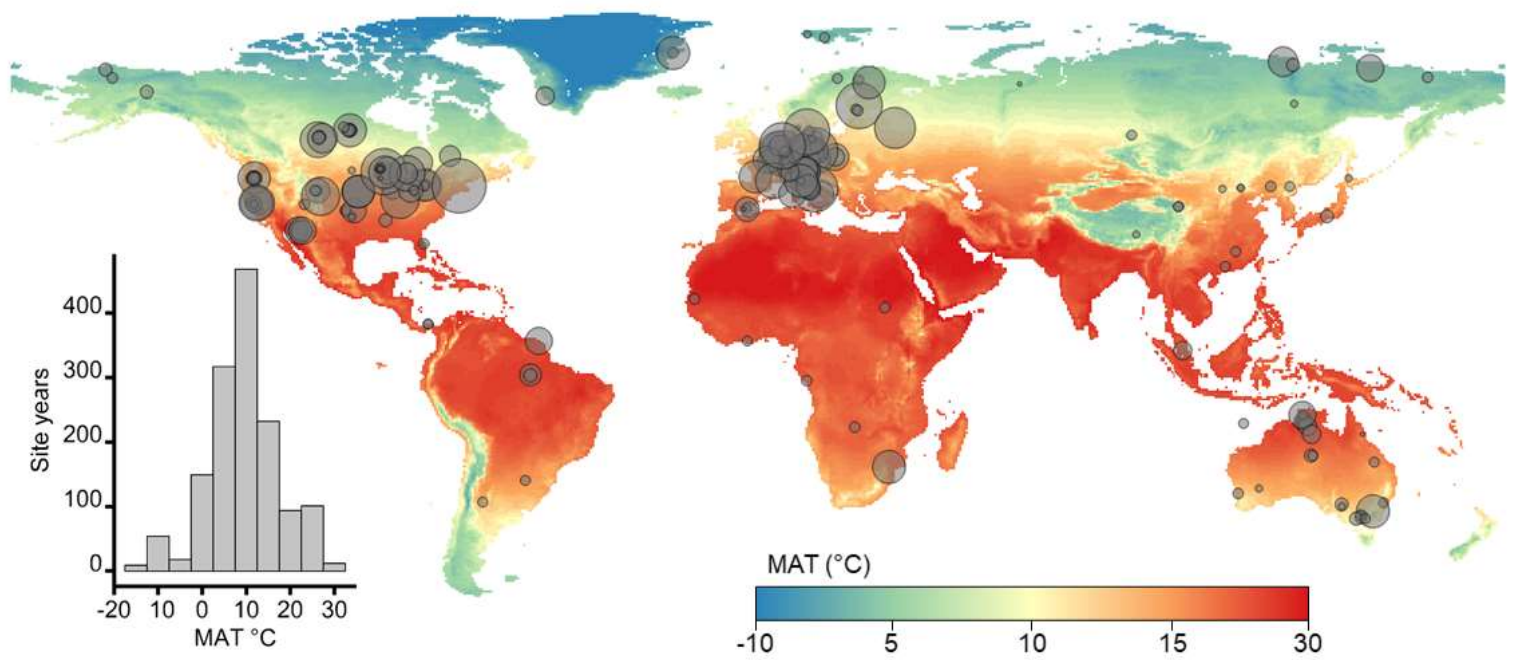

Figure 1. Global distribution of the FLUXNET sites. Site locations $(n=210)$ are displayed over a world mean annual temperature (MAT) map. Symbol diameter represents the number of site years (range: 1 to 22 years) and the inset left-hand figure shows the distribution of site years $(n=1454)$ by MAT. 

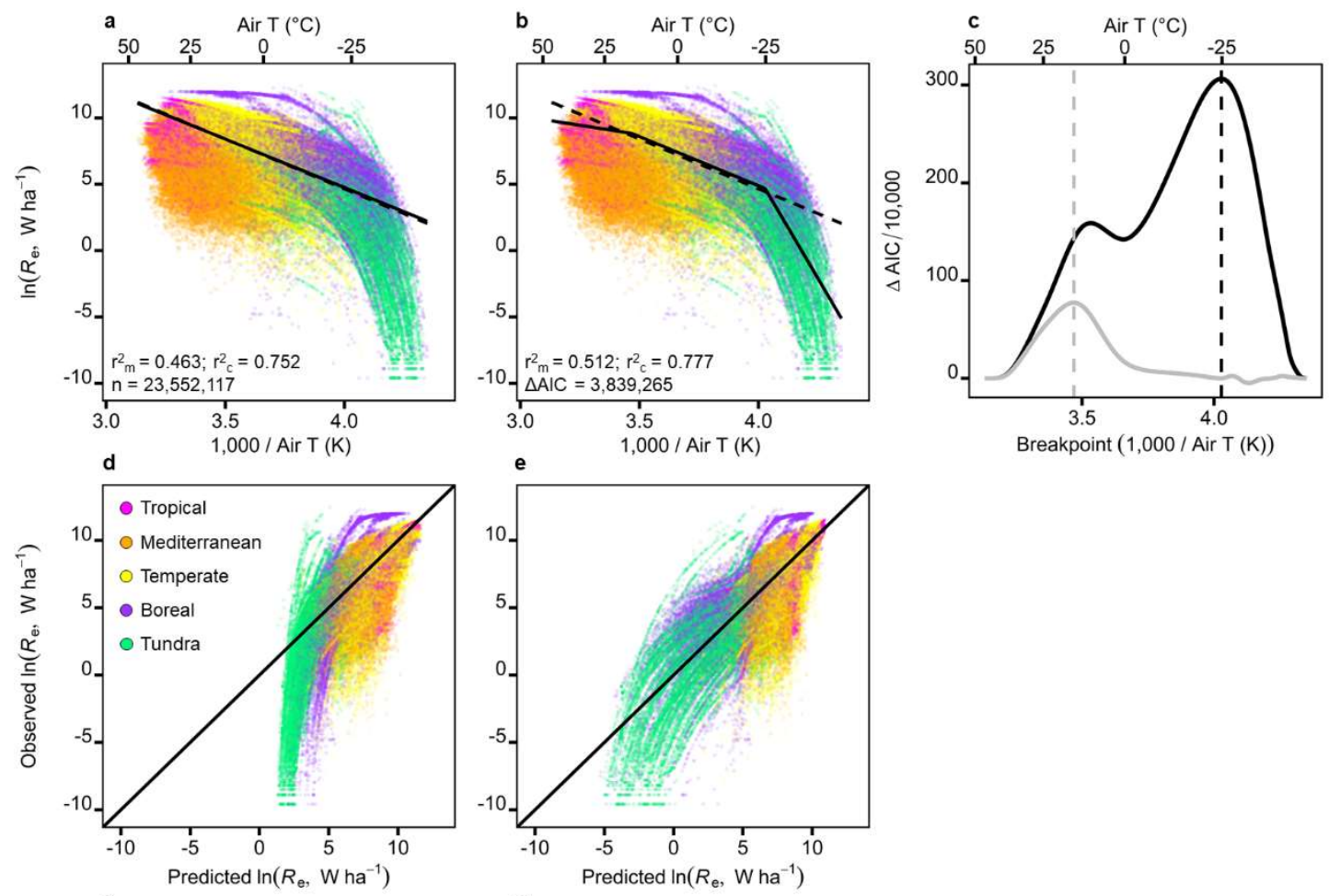

Breakpoint (1,000 / Air T (K))
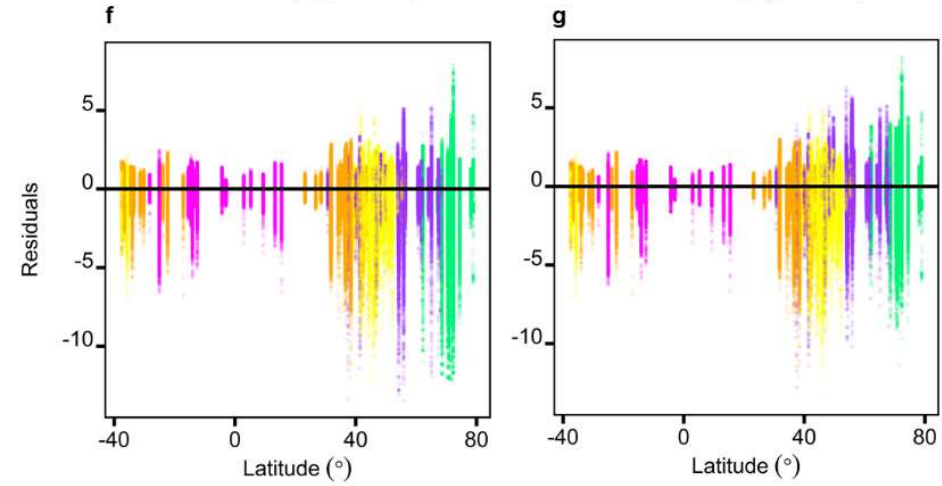

Figure 2. Global extent of the temperature-ecosystem respiration $\left(\boldsymbol{R}_{\boldsymbol{e}}\right)$ relationship. Night-time

half hourly ecosystem respiration measurements from the FLUXNET dataset (symbols), broadly classified as tropical (magenta), mediterranean (orange), temperate (yellow), boreal (purple) or tundra (green) climates. Left-hand plots (a, d \& f) present predictions from the linear model (Eq. 1) and middle plots (b,e \& g) from a threshold model with two temperature breakpoints (Eq. 2), of the temperature-ecosystem respiration relationship. The right-hand plot (c) shows the presence of two temperature breakpoints (black line: air $(1,000 / T)=4.027,-24.8^{\circ} \mathrm{C}$; grey line: air $(1,000 / T)=3.469$, $\left.15.1^{\circ} \mathrm{C}\right)$, identified by the threshold models performance ( $\triangle \mathrm{AIC}$ 's compared to the linear model where higher values provide a better fit to the FLUXNET dataset). Goodness of fit measures indicate the pseudo $r^{2}$ for marginal (fixed) effects $\left(r^{2} \mathrm{~m}\right)$ and conditional (fixed and random) effects $\left(r^{2}\right)$, with top plots (a \& b) showing predictions of the fixed effects only (temperature, solid lines) in each model compared to the activation energy of $-7.50 \mathrm{~K}$ predicted by metabolic theory (dashed lines, $\mathrm{r}^{2} \mathrm{~m}=0.361$; $\left.r^{2}{ }_{c}=0.542\right)$. Middle plots ( $d \& e$ ) present model predictions against observed FLUXNET measurements (solid black 1:1 lines would demonstrate perfect prediction), and bottom plots (f \& g) show model residuals against latitude. Full details of the linear mixed effects models are presented in Supplementary Table 1. 

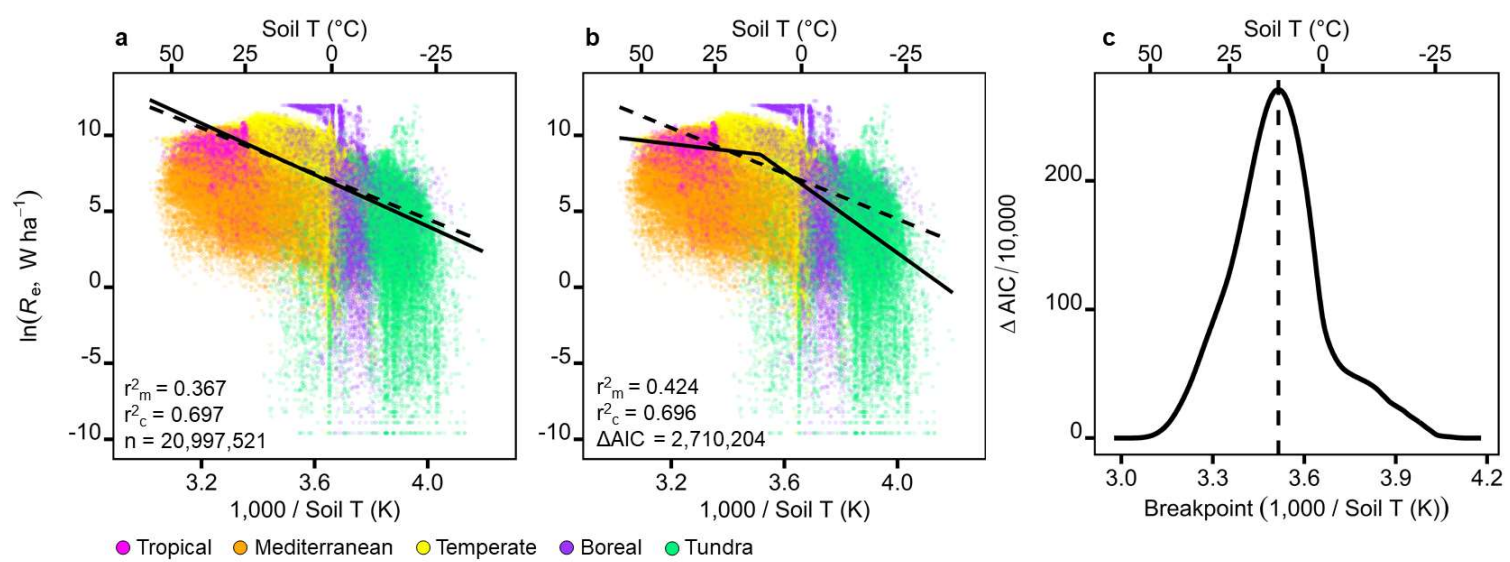

Figure 3. The global soil temperature-ecosystem respiration relationship. Night-time half hourly

423 ecosystem respiration measurements from the FLUXNET dataset (symbols), broadly classified by

424 climate with symbol colours as in Figure 2. Predictions of the temperature-ecosystem respiration

425 relationship are compared for a) the linear model and b) the threshold model, for the fixed effects of

426 temperature (solid lines). Both models are compared to the activation energy of $-7.50 \mathrm{~K}$ predicted by

427 metabolic theory (dashed lines, $r^{2} m=0.173, r_{c}^{2}=0.500$ ). The right-hand plot (c) shows the presence of

428 a single temperature breakpoints (black line: soil $(1,000 / T)=3.515,11.4{ }^{\circ} \mathrm{C}$ ), identified by the

429 threshold models performance ( $\triangle A I C$ 's compared to the linear model where higher values provide a

430 better fit to the FLUXNET dataset). Full details of the linear mixed effects models are presented in

431 Supplementary Table 2.

432 

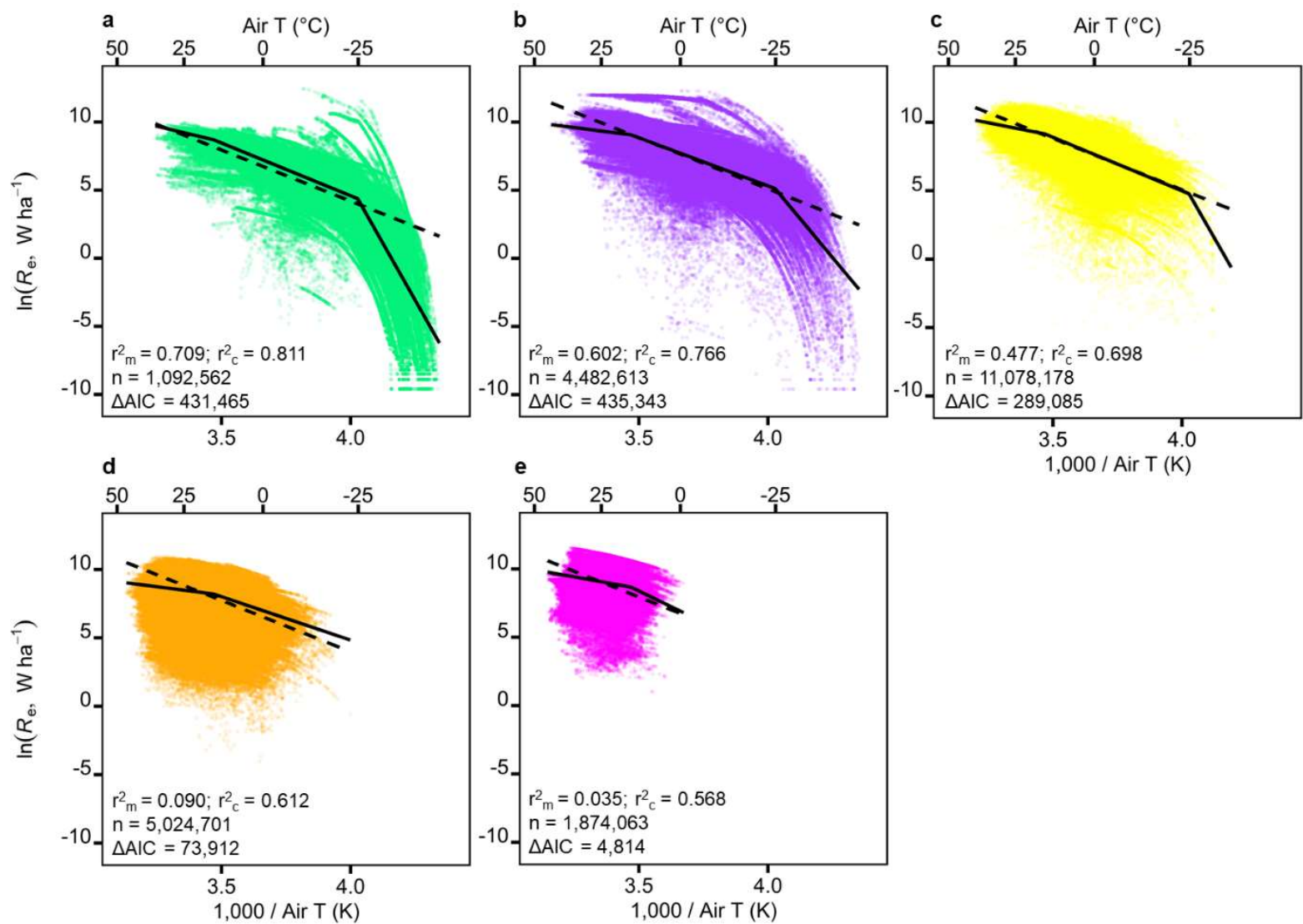

$1,000 /$ Air T (K)

Figure 4. Temperature thresholds of ecosystem respiration $\left(R_{e}\right)$ across five climates. Night-time half hourly ecosystem respiration measurements from the FLUXNET dataset (symbols), classified as a) tundra, b) boreal), c) temperate, d) mediterranean, and e) tropical, with symbol colours as in Figure 2. Solid lines show threshold model predictions for the fixed effects of temperature, and dashed lines show an activation energy of $-7.5 \mathrm{~K}$ predicted by metabolic theory. $\triangle \mathrm{AICs}$ indicate a greater goodness of fit of the threshold compared to linear model. Full details of the linear mixed effects models are presented in Supplementary Table 4. 

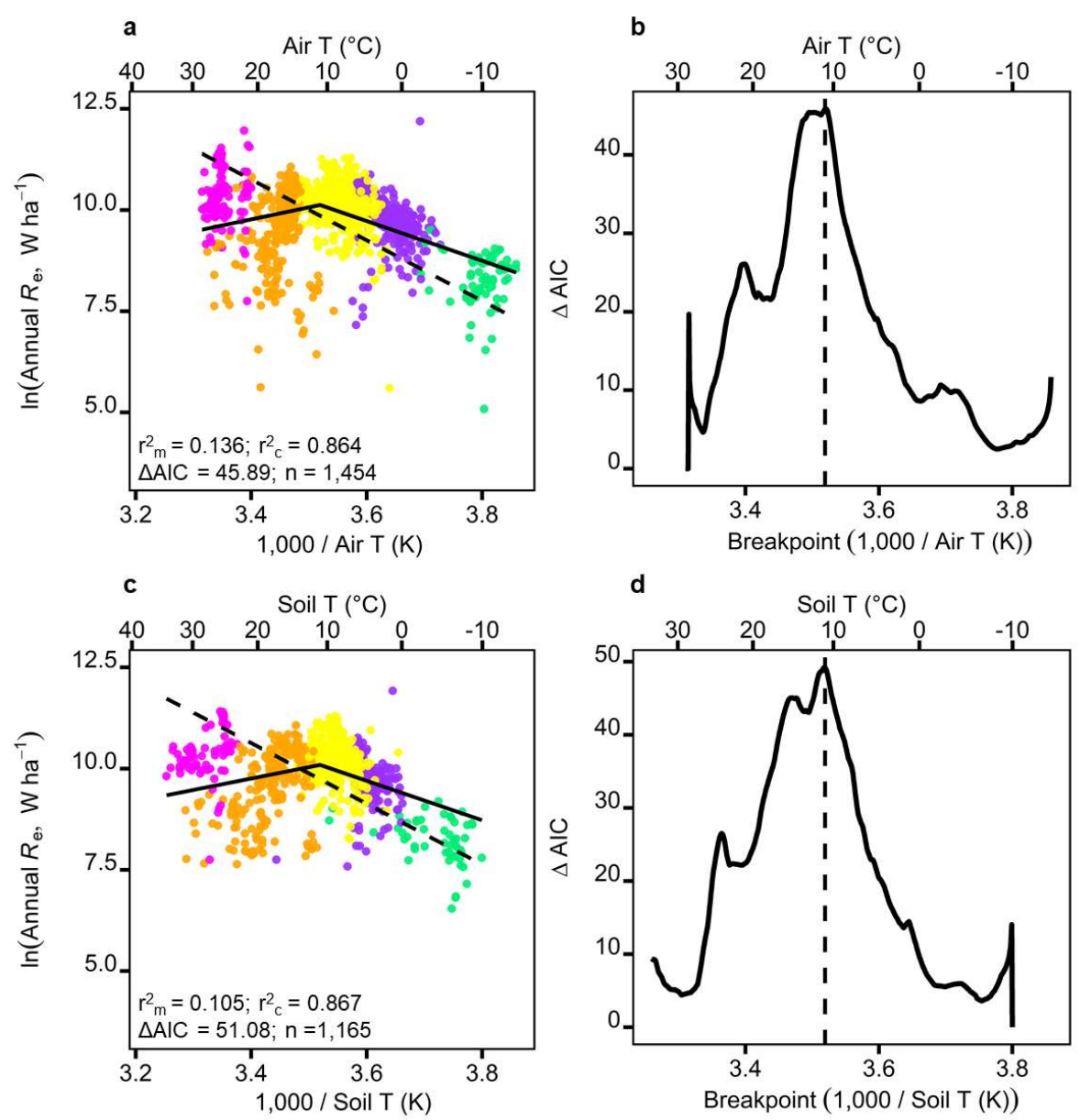

442

Figure 5. Long-term temperature thresholds of ecosystem respiration $\left(\boldsymbol{R}_{e}\right)$. Mean annual $R_{e}$ and either a) air or c) soil temperature measurements (symbols), with symbol colours representing climate as in Figure 2. Plots show predictions from the threshold model (solid lines, for the fixed effects of temperature only). Both threshold models identified a single temperature breakpoint of $11.0{ }^{\circ} \mathrm{C}$, with little support for a second temperature breakpoint $(\triangle \mathrm{AIC}<5$ and $p>0.05)$. Dashed lines indicate an activation energy of $-7.50 \mathrm{~K}$ as predicted by metabolic theory and $\triangle \mathrm{AICs}$ are between the linear and threshold models. Full details of the threshold mixed effects models are presented in Supplementary Table 6.

\section{Data availability}

The dataset analysed during the current study is available on Dryad

(https://doi.org/10.5061/dryad.70rxwdbwk).

\section{Code availability}

The R code used for analysis during the current study is available on Dryad

\section{(https://doi.org/10.5061/dryad.70rxwdbwk).}




\section{Acknowledgements}

459 This work used eddy covariance data acquired and shared by the FLUXNET community and

460 was supported by a Leverhulme Trust Research Project Grant (RPG-2017-071) and a

461 Leverhulme Trust Research Leadership Award (RL-2019-012) to CV. AM was supported by 462 BBSRC (BB/S019952/1) and the Leverhulme Trust (RPG-2019-170), PDB by the US

463 Department of Energy Office of Science (7094866), DB by French Agence Nationale de la

464 Recherche (ANR-10-LABX-25-01; ANR-11-LABX-0002-01), JD by the Ministry of Education,

465 Youth and Sports of the Czech Republic (LM2015061), CG by a National Science

466 Foundation Award (1655095), and AV by RFBR project 19-04-01234-a. We also thank

467 Joanna Baker, George Butler and Ana Navarro Campoy for helpful discussions.

\section{Author contributions}

469 ASAJ and CV developed the methodology and led the writing of the manuscript. ASAJ and 470 AM conduced the data analysis. JA, NA, DB, AB, PDB, CB, AC, JD, AG, BG, IG, CMG, HI, 471 RJ, HK, VM, GM, LM, FEM, JEO, TS, CS, TT, GW, SW, WW, and AV contributed data. All 472 authors contributed to manuscript revisions.

\section{Competing interests}

474 The authors declare no competing interests. 